Supporting information

\title{
Highly Anion Conductive Polymers: How Do Hexafluoroisopropylidene Groups Affect Membrane Properties and Alkaline Fuel Cell Performance?
}

Taro Kimura,,$^{\dagger}$ Akinobu Matsumoto,,+ Junji Inukai, ${ }^{* \neq, \|}$ and Kenji Miyatake ${ }^{*,+, \|}$

$\dagger$ Interdisciplinary Graduate School of Medicine and Engineering, University of Yamanashi, 4

Takeda, Kofu, Yamanashi 400-8510, Japan

Fuel Cell Nanomaterials Center, University of Yamanashi, 6-43 Miyamae-cho, Kofu,

Yamanashi 400-0021, Japan

" Clean Energy Research Center, University of Yamanashi, 4 Takeda, Kofu, Yamanashi 400-8510, Japan

* Corresponding authors.

E-mail addresses: jinukai@yamanashi.ac.jp (J. I.), miyatake@yamanashi.ac.jp (K. M.) 


\section{Materials.}

Monomers 1 and $\mathbf{2}$ were synthesized as reported previously. ${ }^{29,30} \mathrm{~N}, \mathrm{~N}$-dimethylacetamide (DMAc) ( $>99 \%$, Kanto Chemical) was dehydrated over molecular sieve 4A prior to use. 2,2'-Bipyridine $(>99 \%, \quad \mathrm{TCI}), \quad$ bis $(1,5-$ cyclooctadiene $)$ nickel $(0) \quad\left(\mathrm{Ni}(\operatorname{cod})_{2}\right) \quad(>95 \%, \quad$ Kanto Chemical $)$ hydrochloric acid (35-37\%, Kanto Chemical), potassium hydroxide ( $>86.0 \%$, Kanto Chemical) and dimethyl sulfate ( $>99 \%$, Kanto Chemical) were used as received.

\section{Measurements.}

${ }^{1} \mathrm{H}$ and ${ }^{19} \mathrm{~F}$ NMR (500 MHz) spectra were obtained on a JEOL JNM-ECA500 using deuterated chloroform $\left(\mathrm{CDCl}_{3}\right)$ or dimethylsulfoxide (DMSO- $\left.d_{6}\right)$. Tetramethylsilane (TMS) or the solvent was used as an internal reference. Molecular weight was measured with gel permeation chromatography (GPC) equipped with a Shodex K-805 L column and a Jasco UV 2077 detector $\left(270 \mathrm{~nm}\right.$ ) with $\mathrm{CHCl}_{3}$ containing $0.02 \mathrm{M}$ triethylamine as eluent. Molecular weight was calibrated with standard polystyrene samples (ranged from $M_{\mathrm{n}}=1.16$ to $2120 \mathrm{kDa}$ ). Solubility of BAF-QAF was tested by dissolving $10 \mathrm{mg}$ of a membrane sample in $\mathrm{MeOSO}_{3}{ }^{-}$form in an organic solvent (1 $\mathrm{mL}$ ) at $80^{\circ} \mathrm{C}$ or boiling temperature. Ion exchange capacity (IEC) was determined by titration. A membrane sample (ca. $20 \mathrm{mg}$ ) in chloride ion form was immersed in $0.2 \mathrm{M} \mathrm{NaNO}_{3}(12.5 \mathrm{~mL}$ ) at $40{ }^{\circ} \mathrm{C}$ for $24 \mathrm{~h}$. The amount of chloride ions released from the membrane was titrated with $0.01 \mathrm{M}$ 
$\mathrm{AgNO}_{3}$ using $\mathrm{K}_{2} \mathrm{CrO}_{4}$ as an indicator and $\mathrm{NaHCO}_{3}$ as a $\mathrm{pH}$ adjuster.

For transmission electron microscopic (TEM) observation, membrane samples were stained with tetrachloroplatinate ions by ion exchange of the ammonium groups in $0.5 \mathrm{M} \mathrm{K}_{2} \mathrm{PtCl}_{4}$ aqueous solution, rinsed with deionized water, and dried in a vacuum oven overnight. The stained membrane was embedded in an epoxy resin, sectioned to $50 \mathrm{~nm}$ thickness with a Leica microtome Ultracut UCT, and placed on a copper grid. Images were taken on a Hitachi H-9500 transmission electron microscope with an accelerating voltage of $200 \mathrm{kV}$. SAXS profiles were collected using a Nano-Viewer (Rigaku) with $\mathrm{Cu}(\mathrm{K} \alpha)$ as an X-ray source. The SAXS measurement was performed at $40{ }^{\circ} \mathrm{C}$ under nitrogen atmosphere humidified at $30-90 \% \mathrm{RH}$. The membrane sample in chloride ion form was placed in an SAXS cell and equilibrated in the humidified nitrogen for $2 \mathrm{~h}$ before the measurement.

Hydroxide ion conductivity of the membranes was measured in degassed, deionized water (18 $\mathrm{M} \Omega$ ) at $30,40,60$, and $80{ }^{\circ} \mathrm{C}$ using a 4-probe conductivity cell attached with an $\mathrm{AC}$ impedance spectroscopy (Solartron 1255B, Solartron Inc.). Ion conducting resistance $(R(\Omega))$ was determined from the impedance plot obtained in the frequency range from 1 to $10^{5} \mathrm{~Hz}$. The hydroxide ion conductivity $(\sigma)$ was calculated from the equation, $\sigma=l / A R$, where $A\left(\mathrm{~cm}^{2}\right)$ and $l$ (cm) are the cross-sectional area of the membrane and the distance between two reference electrodes, respectively. The water uptake was calculated using the following equation: Water 
uptake $(\%)=\left(W_{\mathrm{w}}-W_{\mathrm{d}}\right) / W_{\mathrm{d}} \times 100$, where $W_{\mathrm{w}}$ is the wet weight and $W_{\mathrm{d}}$ the dry weight (dried in a vacuum oven at $80^{\circ} \mathrm{C}$ overnight) of the membrane.

Humidity dependence of water uptake and $\mathrm{Cl}^{-}$conductivity of the membranes were measured at $40{ }^{\circ} \mathrm{C}$ by a solid electrolyte analyzer system (MSBAD-V-FC, Bel Japan Co.) equipped with a temperature and humidity controllable chamber and magnetic suspension balance. The membranes were kept at $40{ }^{\circ} \mathrm{C}$ for $3 \mathrm{~h}$ under vacuum to obtain the dry weight and exposed to the set humidity for at least $2 \mathrm{~h}$ to obtain the hydrated weight. In-planeion conductivity of the membranes was measured by ac impedance spectroscopy (Solartron 1255B and 1287) simultaneously in the same chamber conducting area, respectively. Ion conducting resistance values were determined from the impedance plot measured over the frequency range from 1 to $10^{5} \mathrm{~Hz}$

Dynamic mechanical analysis (DMA) was carried out with an ITK DVA-225 dynamic viscoelastic analyzer. The Tensile mode was applied, and the strain was controlled to $0.05 \%$. Temperature dependence of storage modulus $\left(\mathrm{E}^{\prime}(\mathrm{Pa})\right)$, loss modulus $\left(\mathrm{E}^{\prime \prime}(\mathrm{Pa})\right)$, and $\tan \delta(=$ E''/E') at $60 \% \mathrm{RH}$ and $10 \mathrm{~Hz}$ was measured for the membranes in chloride ion forms $(5 \times 30$ $\mathrm{mm}$ ) between r.t. and $95^{\circ} \mathrm{C}$ at a heating rate of $1{ }^{\circ} \mathrm{C} \min ^{-1}$. Humidity dependence of E', E', and $\tan \delta$ at $80{ }^{\circ} \mathrm{C}$ and $10 \mathrm{~Hz}$ was also measured between $0 \%$ and $90 \% \mathrm{RH}$ at a humidifying rate of $1 \%$ RH $\min ^{-1}$. 
Tensile strength testing was carried out with a Shimadzu universal testing instrument Autograph AGS-J500N equipped with a temperature and humidity controllable chamber. A membrane sample in chloride ion form was cut into a dumbbell shape $(35 \times 6 \mathrm{~mm}$ (total) and $12 \times 2 \mathrm{~mm}$ (test area)). Stress strain curves were obtained at $80{ }^{\circ} \mathrm{C}$ and $60 \% \mathrm{RH}$ at a stretching rate of $10 \mathrm{~mm}$ $\min ^{-1}$ after equilibrating the membrane at least for $3 \mathrm{~h}$. Alkaline stability test of the membranes was performed in $1 \mathrm{M}, 4 \mathrm{M}$ and $8 \mathrm{M} \mathrm{KOH}$ aqueous solution at $80{ }^{\circ} \mathrm{C}$. The hydroxide ion conductivity was recorded in degassed water at $40{ }^{\circ} \mathrm{C}$ as a function of the testing time. The post-test membranes were subjected to ${ }^{1} \mathrm{H}$ NMR spectra. 


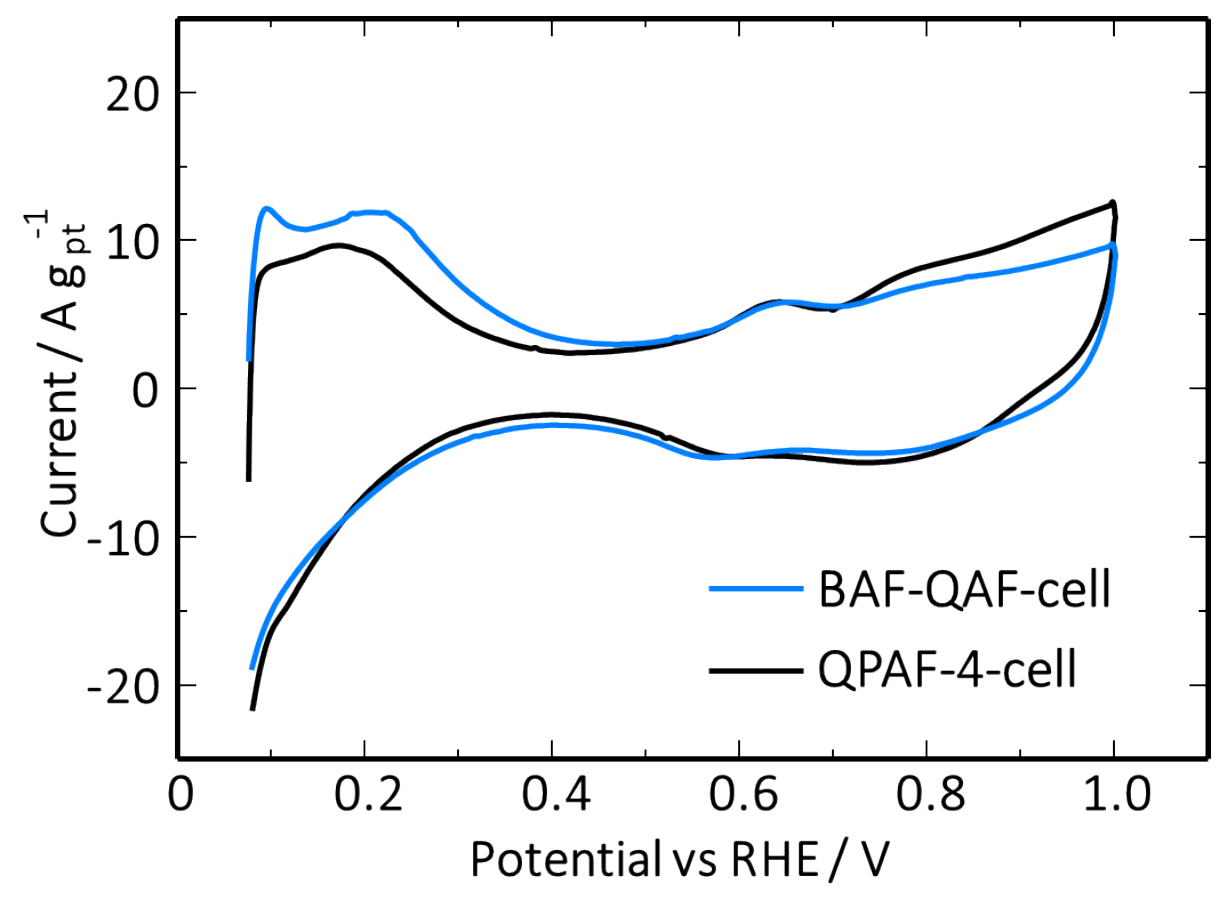

Figure S1. Cyclic voltammograms of the cathodes of BAF-QAF-cell and QPAF-4- cell at $60{ }^{\circ} \mathrm{C}$ and $100 \%$ RH. 


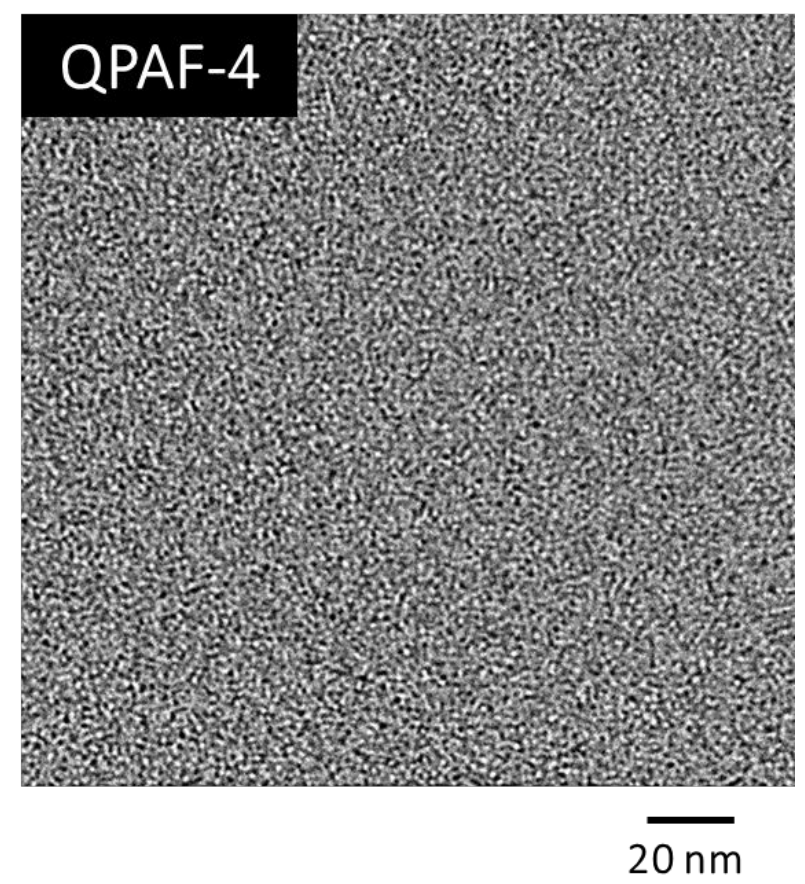

Figure S2. Cross-sectional TEM image of the QPAF-4 (2.1 mequiv $\left.\mathrm{g}^{-1}\right)$ membrane stained with tetrachloroplatinate ions. 